УДК 621.822.681.2:369.64

DOI $10.36910 / 6775-2313-5352-2020-16-15$

Сачковська Л.О.

Луцький національний технічний університет

\title{
МОДЕЛЮВАННЯ ТЕМПЕРАТУРНИХ ПРОЦЕСІВ ПЕРЕРИВЧАСТОГО ШЛІФУВАННЯ ПОВЕРХОНЬ ОБЕРТАННЯ КІЛЕЦЬ РОЛИКОПІДШИПНИКІВ
}

В даній роботі проведена серія експериментальних досліджень, що підтвердила результати моделювання температурних процесів в зоні безиентрового переривчастого шліфування поверхонь кілець кочення роликопідшипників. Експериментально встановлені залежності між температурою шліфування, тангенціальною складовою $P_{z} i$ радіальною складовою $P_{y}$ під час переривчастого шліфування кругами з різними числами канавок. На підставі використання запропонованої збірної конструкиіі переривчастого шліфувального круга розроблена високоефективна технологія безцентрового иліфування поверхонь кілеиь роликопідшипників з можливістю керуванням зернистістю збірної, робочої, калібрувальної та виходжувальної зони різання. Поєднання різної зернистості в конструкції збірного шліфувального круга дало змогу покращити показники якості шліфованих поверхонь до Ra 1,01,4 мкм, знизити та стабілізувати температуру в зоні шліфування до $450^{\circ} \mathrm{C}$ та вилучити з технологічного процесу шліфування базової поверхні кільия одну операцію напівчорнового шліфування.

Ключові слова: круг, канавка, інструмент, кільце, температура, якість.

Особливо актуальним питання зниження теплонапруженості та стабілізації процесу шліфування виявляється при обробленні плоских поверхонь, яке супроводжується підвищеним зношенням шліфувального круга та високими контактними температурами внаслідок значної площі контакту круга з заготовкою. [1-9]

Встановимо характер зміни товщини поверхневого шару оброблюваної деталі, в якому концентрується тепло, що дорівнює довжині сегмента $l_{2}$. Під час цього будемо вважати, що $\theta_{2}=\theta$

Тоді:

$$
l_{2}=\frac{\lambda \cdot S \cdot \theta}{N} .
$$

Встановлено, що потужність теплового потоку $N$ визначається залежністю $N=\sigma \cdot S \cdot V_{p i з}$. Підставивши їі в залежність (1), отримаємо:

$$
l_{2}=\frac{\lambda \cdot \theta}{\sigma \cdot V_{p i s}} \text {. }
$$

3 урахуванням прийнятого значення:

$$
z=\frac{\theta}{\left(\frac{\sigma}{c \cdot p}\right)}
$$

Залежність (2) запишемо у наступному вигляді:

$$
l_{2}=\frac{\lambda \cdot z}{c \cdot p \cdot V_{p i з}}=\frac{\lambda}{c \cdot p \cdot V_{p i 3}} \cdot \bar{l}_{2},
$$


де $\bar{l}_{2}=z$.

Порівнюючи залежності (1) і (3), бачимо, що вони відрізняються тільки другим безрозмірним множником. [1-8]

На рис. 1 зображено характер зміни безрозмірних величин $\bar{l}_{1}$ і $\bar{l}_{2}$ в залежності від показника приведеної температури $z$, який змінюється в межах $0 \ldots 1$. Бачимо, що зі збільшенням $z$ безрозмірна величина $\bar{l}_{1}$ безперервно збільшується, прямуючи до нескінченості (при значенні $z \rightarrow 1$ ). Безрозмірна величина $\bar{l}_{2}$ збільшується згідно лінійного закону зі збільшенням величини $z$ (в межах $z=0 . .1$ Коли ж $\omega \geq 1$ функція $\bar{l}_{2}$ не існує.

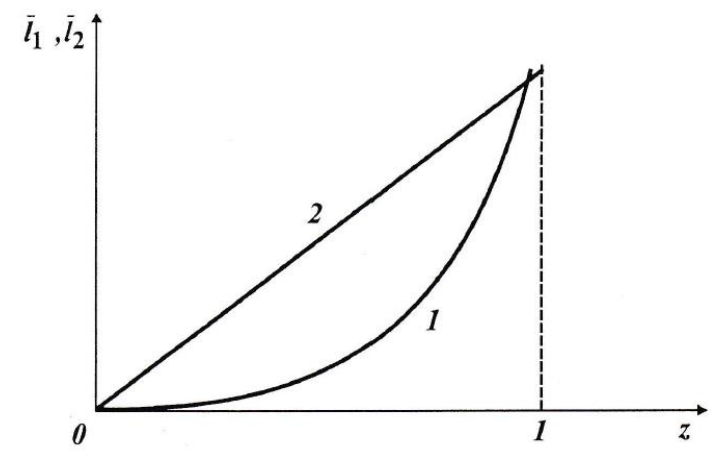

Рис. 1. Характерні зміни безрозмірних величин $\bar{l}_{1}(1)$ і $\bar{l}_{2}(2)$ в залежності від значення показника приведеної температури $z$

Використовуючи вираз для визначення кількості тепла, яке витрачається на нагрівання адіабатичних сегментів $\left(l_{1}+l_{2}\right)$ загальна кількість тепла $Q$ може бути визначена за формулою [8]:

$$
Q=N \cdot \tau
$$

де $N$ - потужність теплового потоку; $\tau$ - час за який перерізається сегмент довжиною $l_{1}$, та дорівнює часу впливу теплового потоку $[1,4,5,7,8]$.

В результаті проведених розрахунків було отримано інтегральне рівняння, в якому невідомі величини $\theta_{2}$ та $\theta$, залежать від часу $\tau$. Для спрощення вирішення рівняння (4) виконаємо диференціювання його правої та лівої частин за часом $\tau$, тобто проведемо диференціювання всіх складових рівняння :

$$
c \cdot p \cdot S \cdot V_{p i 3} \cdot \theta(\tau)+c \cdot p \cdot \lambda \cdot S^{2} \cdot \frac{\theta_{2} \cdot \theta_{2}^{\prime}}{N}=N
$$

Де $\theta_{2}^{\prime}$ - перша похідна функції $\theta_{2}$ по часу $\tau ; \theta(\tau)$ - температура на останньому елементарному відрізку сегмента довжиною $l_{1}$, тобто по довжині сегмента $l_{1} \cdot[6,7,8]$

Бачимо, що $\theta(\tau)=\theta_{2}$. Тоді рівняння (5) набуде остаточного вигляду:

$$
c \cdot p \cdot S \cdot V_{\text {різ }} \cdot \theta_{2}+c \cdot p \cdot \lambda \cdot S^{2} \cdot \frac{\theta_{2} \cdot \theta_{2}^{\prime}}{N}=N \text {. }
$$

Оскільки рівняння (2) не вдалось вирішити в явному вигляді відносно температури $\theta$, то використаємо залежність , яка дозволяє температуру $\theta$ виразити через показник приведеної температури $\omega$. Тоді, виходячи з залежності (2), отримаємо:

$$
\theta^{\prime}=\frac{\sigma}{c \cdot p} \cdot z^{\prime}
$$


де $\theta^{\prime}$ і $z^{\prime}$-похідні функцій $\theta^{\prime}$ і $z^{\prime}$ за часом $\tau$. [8]

Для визначення похідної $\omega^{\prime}$ виконаємо диференціювання лівої та правої частин рівняння за часом. Очевидно, перша похідна лівої частини рівна одиниці, а правої частини: $-\frac{\lambda}{c \cdot p \cdot V_{p i з}^{2}} \cdot\left[\frac{-z^{\prime}}{(1-z)}+z^{\prime}\right]$. В результаті рівняння (6) набуде вигляду:

$$
1=-\frac{\lambda}{c \cdot p \cdot V_{p i 3}^{2}} \cdot z^{\prime} \cdot\left[\frac{-1}{(1-z)}+1\right]
$$

звідки

$$
z^{\prime}=\frac{c \cdot p \cdot V_{p i 3}^{2}}{\lambda} \cdot \frac{(1-z)}{z}
$$

Підставимо вирази (6), (7) в початкове диференційне рівняння, та виразимо потужність теплового потоку $N: N=S \cdot \sigma \cdot V_{p i з}$.

Повернемося до рівняння:

$$
z+(1-z)=1
$$

В даному рівнянні ліва і права частини рівні між собою. Можна зробити висновок, що функція температури $\theta$, яку ми шукали визначена правильно. [1-6]

Було визначено [9]кількість тепла $Q_{1} / Q$, що витрачається на нагрівання ділянки досліджуваного адіабатичного сегмента довжиною $l_{1}$, і кількість тепла $Q_{2} / Q$, що витрачається на нагрівання ділянки досліджуваного адіабатичного сегмента довжиною $l_{2}$, виходячи із рівняння балансу тепла:

$$
\frac{Q_{1}}{Q}+\frac{Q_{2}}{Q}=1
$$

Ліва і права частини рівняння (9) рівні між собою, тобто величина $\mathrm{z}$, яку ми шукали ,описана залежністю (8), визначена правильно.

$$
\frac{Q_{1}}{Q}=1-\frac{z^{2}}{2 \cdot \bar{l}_{1}} ; \frac{Q_{2}}{Q}=1-\frac{z^{2}}{2 \cdot \bar{l}_{1}}
$$

Чим більша величина $z$, тим більше значення $Q_{1} / Q$ і менше $Q_{2} / Q$. Це означає, що зі збільшенням $z$ кількість тепла $Q_{1} / Q$, яке переходить у стружку збільшується, а кількість тепла $Q_{2} / Q$, що йде в оброблювану деталь - зменшується. 3 цього слідує наступний висновок, що під час шліфувального оброблення, яке характеризується високими температурами різання, кількість тепла, що йде в стружку буде більшою за кількість тепла, яке іде в заготовку. $[1,2,5]$

Для розрахунку i прогнозування відносної величини температури $z$ використана залежність:

$$
z=1-e^{-\frac{c \cdot \rho \cdot V_{p \dot{s}}}{\lambda} \cdot\left(l_{1}+l_{2}\right)}=1-e^{-\left(\bar{l}_{1}+\bar{l}_{2}\right)} .
$$

В попередніх роботах $[8,9]$ встановлено, що відносна величина температури $z$ цілком однозначно визначається сумарною довжиною ділянки стержня $\left(l_{1}+l_{2}\right)$, підданого тепловому впливу. Чим менше дана величина, тим менша відносна величина температури $z$ і відповідно, температура при шліфуванні $\theta$. [1, 3, 5, 7]

Показано, що найбільша температура при шліфуванні переривчастими кругами 
досягається за умови $l_{1}=t$, тобто в момент виходу шліфувального круга 3 контакту 3 розглянутим адіабатичним стержнем. Після перетворень залежність (9) приймає вигляд:

$$
\frac{c \cdot \rho}{\lambda} \cdot Q_{\text {num }} \cdot \sqrt{\frac{t}{2 \cdot R_{k p}}}=\bar{l}_{1},
$$

де $t$ - глибина шліфування, м; $Q_{n u m}-$ питома продуктивність обробки, м ${ }^{3} /($ м $\cdot c) ; V_{\text {деm }}$ - швидкість деталі, м/с; $R_{\kappa p}-$ радіус круга, м. [2-6]

У працях $[8,9$ ]була зроблена кількісна оцінка основних параметрів теплового процесу при плоскому багатопрохідному $\left(t_{1}=0,01 \cdot 10^{-3} \mathrm{M}\right)$ i врізному безцентровому $\left(t_{2}=10^{-3} \mathrm{M}\right)$ шліфуванні найбільш використовуваних загартованих підшипникових сталей ШХ15 і 15Г1, що здійснюється 3 досить високою питомою продуктивністю обробки $Q_{n u m}=500 \mathrm{mм}^{3} /\left(\mathrm{мм}^{*} \times\right.$ в), яка наведена в таблиці 1. [2-5, 9]

Таблиця 1

Розрахункові значення параметрів $\tau, V_{p i 3}, \bar{l}_{1}, z, \theta, \frac{Q_{1}}{Q}, \frac{Q_{2}}{Q}, \frac{Q_{2}}{Q_{1}}, \frac{\bar{l}_{1}}{l_{2}}, V_{\theta}, \frac{V_{\theta}}{V_{p i 3}}$, $(\lambda=50 \mathrm{BT} /(\mathrm{м} \cdot \mathrm{K}) ; c=175,9$ Дж/(кг $\left.\cdot \mathrm{K}) ; \rho=15 \cdot 10^{3} \mathrm{\kappa} / \mathrm{m}^{3} ; 2 R_{\kappa p}=0,3 \mathrm{м}\right)$.

\begin{tabular}{|l|l|l|l|l|l|l|l|l|l|l|l|}
\hline Вид шліфування & $\begin{array}{l}\tau \cdot \\
10^{-2}, \\
\mathrm{c}\end{array}$ & $\begin{array}{l}V_{p i 3} \cdot \\
10^{-3} \\
\mathrm{~m} / \mathrm{c}\end{array}$ & $\begin{array}{l}\bar{l}_{1} \cdot \\
10^{-2}\end{array}$ & $\begin{array}{l}z^{-2} \\
10^{-2}\end{array}$ & $\theta, \mathrm{K}$ & $\frac{Q_{1}}{Q}$ & $\frac{Q_{2}}{Q}$ & $\frac{Q_{2}}{Q_{1}}$ & $\frac{\bar{l}_{1}}{l_{2}}$ & $\begin{array}{c}V_{\theta} \cdot \\
10^{-3}, \\
\mathrm{~m} / \mathrm{c}\end{array}$ & $\frac{V_{\theta}}{V_{p i 3}}$ \\
\hline $\begin{array}{l}\text { Плоске } \\
\text { багатопрохідне }\end{array}$ & 0,15 & 5,6 & 0,2 & 7,5 & 463 & 0,04 & 0,92 & 17,0 & 0,03 & 75,2 & 13 \\
\hline $\begin{array}{l}\text { Врізне } \\
\text { безцентрове }\end{array}$ & 171 & 0,55 & 2,9 & 22,6 & 1382 & 0,15 & 0,81 & 5,23 & 0,12 & 2,52 & 4,1 \\
\hline
\end{tabular}

Параметри сталого теплового процесу $(z \rightarrow 1)$, описувані залежностями:

$$
\tau=\frac{\lambda}{c \cdot \rho \cdot V_{p i 3}^{2}} ; l_{2}=\frac{\lambda}{c \cdot \rho \cdot V_{p i 3}} ; \theta=\frac{\sigma}{c \cdot \rho} ; V_{p i 3}=V_{\text {дет }} \cdot \sqrt{\frac{t}{2 \cdot R_{\kappa p}}},
$$

розраховані для умов шліфування суцільними кругами і характеризуються досить великими значеннями, що свідчить про наявність несталого теплового процесу. Сталий тепловий процес реалізується за умови запровадження для шліфування переривчастих шліфувальних кругів.

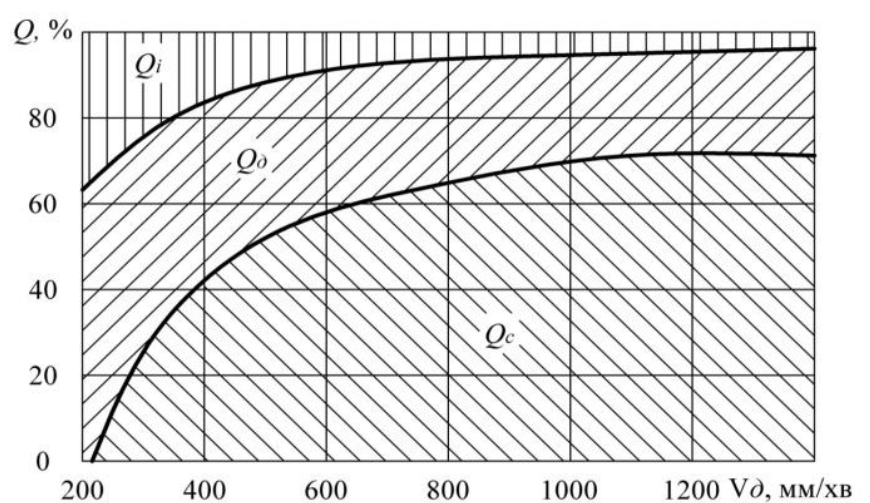

Рис. 1.1. Розподіл тепла $Q$ між елементами технологічної системи

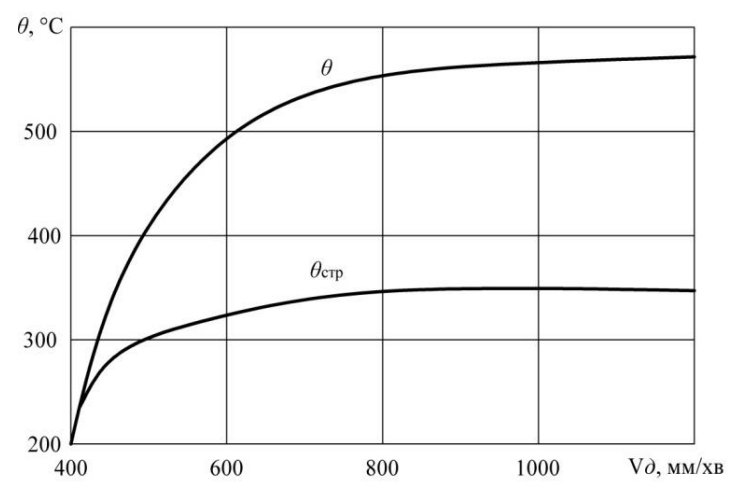

Рис. 1.2. Вплив швидкості різання $V$ на температуру шліфування $\theta$ і середню температуру стружки $\theta_{c m p}$ (сталь ШХ15) 
На рис. 1.2 зображено вплив швидкості різання на розподіл тепла між стружкою, деталлю та інструментом. Як видно, розподіл тепла між стружкою, деталлю та інструментом безпосередньо залежить від швидкості різання. 3 рис. 1.2 видно, що кількість тепла, яке йде в стружку, зі збільшенням швидкості різання від 0 до $V=800 \mathrm{Mм} /$ хв, збільшується наближуючись до 20\%. Даний результат було підтверджено теоретичними дослідженнями [5].

Тобто кількість тепла, що йде в стружку, зростає, а те тепло, що йде в деталь та інструмент - зменшується. Такий характер розподілу тепла зумовлений збільшенням температури різання зі збільшенням швидкості різання, рис. 1.1.

Отже, для даних умов оброблення величина $z$ наближається до граничного значення $z \rightarrow 1$, за якого тепловий процес під час шліфування стабілізується. Цим доведено можливість реалізації на практиці значень $z$, які близькі до граничного значення: $z \rightarrow 1$. [1-7]

Час досягнення визначеної температури залежить від швидкості джерела, що дозволяє змінювати цей час у широких межах. Після того, як процес шліфування припинився, наступає невеликий часовий проміжок, протягом якого поверхня охолоджується потоком ЗОР. Проміжок часу між двома сусідніми робочими виступами повинен бути таким, щоб поверхня могла охолонути на визначену величину. Оскільки поверхня в перерві між робочими циклами вільна, теплообмін здатний істотно змінити їі температуру.

Висновки. Визначені основні умови зменшення температури і відповідно підвищення якості оброблення кілець роликопідшипників на операціях безцентрового шліфування, які полягають в зменшенні кількості тепла, що передається в деталь та збільшення кількості тепла, що передається в стружку, за рахунок зменшення величини припуску, швидкості переміщення теплового джерела в глибину поверхневого шару і застосування переривчастих шліфувальних кругів.

\section{Інформаційні джерела}

1. Якимов А.В. Прерывистое шлифование / А.В. Якимов, Ю.А. Бояршинов и др. // Вестник машиностроения. - 1967. - №3. - С. 76-78.

2. Марчук В.I. Класифікація та походження температурних дефектів на операціях безцентрового шліфування поверхонь обертання / Марчук, І.В. Марчук, М.В. Олексин, А.М. Ештеіві / Матеріали Шістнадцятої міжнародної молодіжної науково-технічної конференції «Машинобудування очима молодих: прогресивні ідеї-наука-виробництво», м. Суми, 26-29 жовтня 2016 р. - Суми: Сумський державний університет, 2016. - С. 102-103.

3. Новиков Ф.В., Яценко С.М. Новый упрощенный подход к расчету температуры поверхностного слоя детали при ее механической обработке. - Физические и компьютерные технологии. - Труды 11-й Международной научно-технической конференции, 2-3 июня 2005 г.- Харьков: ХНПК «ФЭД», 2005. - С.137-146.

4. Марчук І.В., Марчук В.І., Модель стабілізації високочастотних коливних процесів в динамічній системі круглого врізного шліфування. Збірник наукових праць. - Луцьк: ЛНТУ, 2016. - Перспективні технології та прилади №9. - С.75-83.

5. Марчук І.В. Керування температурою на безцентрово-шліфувальних операціях / М.В. Олексин, А.М. Ештеіві // "Перспективні технології та прилади". Збірник наукових праць. Випуск 10(1). м. Луцьк, червень 2017 р. - Луцьк: Луцький НТУ, 2017. - С. 133-138.

6. Марчук І.В. Технологічне керування температурою під час безцентрового шліфування функціональних поверхонь обертання/ Марчук В.I. // «Наукові нотатки». Випуск 61. м. Луцьк, 2018 - Луцьк: Луцький НТУ, 2018. - С. 142-147

7. Марчук І.В. Технологічне забезпечення точності шліфування поверхонь обертання підшипників / I.В. Марчук, А.М. Ештеіві, М.В. Олексин / Наукові нотатки: Міжвуз. зб. Луцького національного технічного університету (за напрямком “Інженерна механіка"). Вип. 57. - Луцьк: Луцький НТУ, 2017. - С. 123-127.

8. Марчук І.В. Монографія// Технологічні основи забезпечення й стабілізації якості поверхоньобертання на операціях механічного оброблення //. Луцьк: IBВ Луцького НТУ, 2019.

9. Ештеіві А.М. Автореферат дисертації на здобуття наук.ступеня к.т.н. Технологічне забезпечення якості та точності шліфування кілець роликопідшипників в умовах переналагоджувального виробництва. Луцьк 2017. 8-14С. 


\section{Sachkovska}

Lutsk National Technical University

\section{SIMULATION OF TEMPERATURE PROCESSES OF INTERMITTENT GRINDING OF SURFACES BY ROTATION OF ROLLER BEARING RINGS}

In this work, a series of experimental studies was conducted, which confirmed the results of modeling temperature processes in the area of centerless intermittent grinding of the rolling bearing surfaces of roller bearings. The dependences between the grinding temperature, the tangential component and the radial component during intermittent grinding with circles with different numbers of grooves have been experimentally established. Based on the use of the proposed prefabricated design of the intermittent grinding wheel, a highly efficient technology of centerless grinding of the surfaces of roller bearing rings with the ability to control the grain size of the prefabricated, working, calibration and care cutting zone. The combination of different grain sizes in the design of the prefabricated grinding wheel made it possible to improve the quality of ground surfaces to Ra 1.0-1.4 $\mu \mathrm{m}$, reduce and stabilize the temperature in the grinding zone to $450^{\circ} \mathrm{C}$ and remove from the process of grinding the base surface of the ring one semi-roughing operation .

Key words: circle, groove, tool, ring, temperature, quality.

\section{Сачковска Л.А.}

Луцкий национальный технический университет

\section{МОДЕЛИРОВАНИЕ ТЕМПЕРАТУРНЫХ ПРОЦЕСОВ ПРЕРЫВИСТОГО ШЛИФОВАНИЯ ПОВЕРХНОСТЕЙ ВРАЩЕНИЯ КОЛЕЦ РОЛИКОПОДШИПНИКОВ}

В данной работе проведена серия экспериментальных исследований, подтвердила результаты моделирования температурных процессов в зоне бесиентрового прерывистого шлифования поверхностей колеи качения роликоподшипников. Экспериментально установлень зависимости между температурой шлифовки, тангенциальной составляющей и радиальной составляющей при прерывистого шилифования кругами с разными числами канавок. На основе использования предложенной сборной конструкции прерывистого илифовального круга разработана высокоэффективная технология бесиентрового шлифования поверхностей колеи роликоподшипников с возможностью управлением зернистостью сборной, рабочей, калибровочной и виходжувальнои зонь резания. Сочетание различной зернистости в конструкиии сборного шлифовального круга позволило улучшить показатели качества шлифованных поверхностей до Ra 1,0-1,4 мкм, снизить и стабилизировать температуру в зоне илифования до $450^{\circ} \mathrm{C}$ и исключить из технологического прочесса шлифования базовой поверхности кольца одну операчию напивчорнового шлифовки .

Ключевые слова: круг, канавка, инструмент, кольчо, температура, качество. 